\title{
COMPACTNESS OF INTEGRAL OPERATORS \\ IN LEBESGUE SPACES WITH MIXED NORM
}

\author{
Alberto Fiorenza, BABITA Gupta And PANKAJ JAIN
}

\begin{abstract}
Compactness of certain double sized multidimensional integral operators is characterized in terms of the corresponding two-dimensional operators in the framework of weighted Lebesgue spaces with mixed norm.
\end{abstract} operator

Mathematics subject classification (2000): 46E35, 26D10.

Key words and phrases: Lebesgue space, mixed norm, compactness, Hardy Operator, Hardy-Steklov

\section{REFERENCES}

[1] J. APPEll AND A. KufNeR, On the two dimensional Hardy operator in Lebesgue spaces with mixed norms, Analysis, 15 (1995), 91-98.

[2] A. BenedeK And R. PAnzone, The spaces $L^{p}$ with mixed norm, Duke Math. J., 28 (1961), 301-324.

[3] O. V. BESOV, V. P. IL'IN AND S. M. NIKOL'SKIII, Integral Representations of Functions and Imbedding Theorems, John Wiley \& Sons, 1978.

[4] H. P. HeINIG AND G. SinNAMON, Mapping properties of integral averaging operators, Studia Math., 129 (1998), 157-177.

[5] P. Jain And B. GuPTA, Compactness of Hardy-Steklov operator, J. Math. Anal. Appl., 288 (2003), 680-691.

[6] P. JAIN, P. K. JAIN AND B. GUPTA, On certain double sized integral operators over multidimensional cones, Proc. A. Razmadze Math. Inst., 131 (2003), 39-60.

[7] P. JAIN, P. K. JAIN AND B. GUPTA, Compactness of Hardy type operators over star-shaped regions in $\mathbb{R}^{N}$, Canad. Math. Bull., 47 (2004), 540-552.

[8] P. JAIN, P. K. JAIN AND B. GUPTA, On certain weighted integral inequalities with mixed norm, Italian J. Pure Appl. Math., 17 (2005), 9-20.

[9] A. Kufner, L. Maligranda And L. E. Persson, The Hardy Inequality-About its History and Related Results, Book manuscript, Department of Mathematics, Luleå University of Technology, 2006 (154 pages).

[10] A. KufNer And L. E. Persson, Weighted Inequalities of Hardy Type, World Scientific, 2003.

[11] E. LOMAKINA AND V. D. STEPANOV, On the Hardy-type integral operators in Banach function spaces, Publ. Math. 42 (1998), 165-194.

[12] B. OpIC And A. Kufner, Hardy-Type Inequalities, Pitman Research Notes in Mathematics Series, Longman Scientific \& Technical Harlow, 1990.

[13] E. SAWYER, Weighted inequalities for the two-dimensional Hardy operator, Studia Math., 82 (1985), $1-16$.

[14] G. Sinnamon, One dimensional Hardy-type inequalities in many dimensions, Proc. Royal Soc. Edinburg A, 128 (1998), 833-848.

[15] G. SinnAmon, Hardy-type inequalities for a new class of integral operators, In : Analysis of Divergence, Control and Management of Divergent Process (eds.: W. O. Bray and C. V. Stanojevic), Birkhäuser, Boston, 1999, 297-307.

[16] V. D. StePanOv, Two-weighted estimates for Riemann-Liouville integrals, Report No. 39, Math. Inst., Czechoslovak Academy of Sciences, 1988. 
[17] V. D. STEPANOV, Weighted inequalities of Hardy type for higher order derivatives and their applications, Soviet Math. Dokl. 38 (1989), 389-393.

[18] V. D. StePANOv, Weighted inequalities of Hardy type for higher order derivatives, Proc. Steklov Inst. Math. 187 (1990), 205-220.

[19] V.D. STEPANOV, Weighted inequalities of Hardy type for Riemann-Liouville fractional integrals, Siberian Math. J. 31 (1990), 512-522.

[20] V. D. STEPANOV, On the boundedness and compactness of a class of integral operators, Soviet Math. Dokl. 41 (1990), 468-470.

[21] V. D. STEPANOv, Two-weighted estimates of Riemann-Liouville integrals, Math. USSR-Izv., 36 (1991), $669-681$.

[22] V. D. StePANov, Weighted inequalities for a class of Volterra convolution operators, J. London Math. Soc. 45 (1992), 232-242. 